\title{
A recriação da vida em chatbot e avatares com o uso de dados póstumos
}

\author{
Paula C. N. Silval ${ }^{1}$, Daniele Trevisan ${ }^{2}$, Cristiano Maciel $^{12}$ \\ ${ }^{1}$ Instituto de Computação - Universidade de Mato Grosso (UFMT) \\ Cuiabá-MT-Brasil \\ ${ }^{2}$ Programa de Pós-Graduação em Educação - Universidade de Mato Grosso (UFMT) \\ Cuiabá-MT-Brasil
}

\{paulacgates@gmail.com; daniele.tr@hotmail.com; crismac@gmail.com\}

\begin{abstract}
The recreation of the afterlife from the user's digital legacy is already a reality, which can be conceived via chatbot and avatars. Therefore, we carried out a survey in order to analyze the opinions and acceptance of people in relation to the collection of their personal data, including those from social networks, for a possible posthumous interaction. The qualitative approach research used for data collection was the application of a questionnaire that was answered by 112 people. Based on the survey data, we realized that the opinions of the participants are divided, some find it interesting to use digital immortality to help mourn loved ones, and others problematize issues involving ethics and privacy.
\end{abstract}

Resumo. A recriação da vida após a morte a partir do legado digital do usuário já é realidade, a qual pode ser concebida via chatbot e avatares. Diante disso, realizamos uma pesquisa com o objetivo de analisar as opiniões e a aceitação das pessoas em relação à coleta de seus dados pessoais, incluindo os de redes sociais, para uma possível interação póstuma. A pesquisa de abordagem qualitativa utilizou para a coleta de dados a aplicação de um questionário que foi respondido por 112 pessoas. A partir dos dados da pesquisa percebemos que as opiniões dos participantes estão divididas, alguns acham interessante o uso da imortalidade digital na ajuda com o luto de entes queridos e outros problematizam questões envolvendo ética e privacidade.

\section{Introdução}

Desde os primórdios da humanidade, a morte gera inúmeros questionamentos e, pela dificuldade de respondê-los, principalmente no que se refere à vida após a morte, o ser humano iniciou uma busca para tentar evitá-la de qualquer modo, surgem assim estudos diante da imortalidade.

A imortalidade, ao longo dos séculos, é um tema instigante e, recentemente, tem ganhado destaque na área de tecnologia, com estudos sobre a imortalidade digital. A partir da constituição do legado digital ao longo da vida, que conta com e-mails, fotos, vídeos e outras informações sobre uma pessoa falecida, pesquisas são desenvolvidas para associar o legado digital como uma alternativa para o tratamento da morte no espaço digital. (MACIEL; GALVÃO, 2020) 
Segundo Galvão et al. (2017) a imortalidade digital pode ocorrer de diversas formas, como espaço para homenagens aos mortos (memoriais digitais) e a aplicação de técnicas computacionais para simular comportamentos do morto no espaço digital. Tais iniciativas buscam contribuir para uma ressignificação da morte no meio digital e contribuem nos processos de vivência do luto.

Neste estudo partimos da seguinte questão norteadora: os usuários são favoráveis sobre o fornecimento de informações durante alguns anos de sua vida para uso póstumo via um chatbot, por exemplo, ou um avatar em uma realidade virtual? Acreditamos que seja fundamental compreender a aceitação dos usuários em relação à coleta de dados pessoais e sobre suas percepções sobre o tema. Diante disso, esse artigo tem como objetivo analisar as opiniões e a aceitação das pessoas em relação à coleta de seus dados pessoais, incluindo os de redes sociais, para uma possível interação póstuma.

Sob o ponto de vista metodológico, esta pesquisa consiste em uma análise exploratória com abordagem qualitativa. Para a coleta de dados aplicamos um questionário no período de 11/05/2021 à 08/06/2021, no qual obtivemos um retorno de 112 respostas. A partir das respostas, procedemos através da técnica de análise de conteúdo e apresentamos neste texto os principais resultados da pesquisa.

Para tanto, apresentamos inicialmente o referencial teórico em que apresentamos os conceitos que embasam as discussões, trazemos o detalhamento da metodologia, abordando as etapas desenvolvidas na pesquisa. Na sequência, apresentamos os resultados e a discussão dos dados. Finalizamos com as considerações finais e referências.

\section{Referencial Teórico}

Nesta seção, apresentamos o referencial teórico que nos orienta nas análises e discussões, são artigos lidos durante o trajeto da pesquisa no que se refere a Imortalidade Digital, Avatares e Legado Digital.

Primeiramente, é importante ter como base o conceito de interação póstuma, o qual, segundo Maciel e Pereira (2012) é a interação em um sistema com os dados de pessoas falecidas ou de outros usuários com as pessoas falecidas, considerando que póstuma é a interação com os dados de alguém falecido e não o dado em si, que foi produzido durante a vida.

Uma possibilidade de promoção deste tipo de interação é via imortalização digital de indivíduos. Bell e Gray (2001), apontam que a Imortalidade Digital se trata da experiência e aprendizado sem fim e utiliza da tecnologia para o fazer ou, de forma análoga, Galvão e Maciel (2020) descrevem como: "a imortalidade digital refere à preservação da identidade digital de um usuário, mantendo-a ativa mesmo depois do falecimento deste." Um exemplo do crescimento dessa área são algumas plataformas que já mostram uma preocupação com o pós-mortem de seus usuários, como o Facebook utilizando de herdeiros e memoriais digitais, ou então empresas que já possuem o serviço de um testamento digital, desejos e mensagens que o usuário pode personalizar antes de sua morte. Existem ainda, alguns serviços que pretendem ir além, tentando oferecer uma experiência mais completa, com técnicas mais avançadas que se utilizam da inteligência artificial.

Considerando essas possibilidades para a imortalidade e para o legado digital, cabe ressaltar o crescimento do estudo nas áreas de WBE (Whole Brain Emulation) ou 
"Upload" da mente para um computador. É indubitável que os estudos acerca do "Upload" ainda são muito novos e poucos embasados, isto é, a complexidade do cérebro humano, com mais de 80 bilhões de neurônios e interações sinápticas, ainda é pouco compreendido e, dificilmente, pode ser replicado no contexto atual apesar de que o campo da computação e neurociência já conseguiu grandes avanços na simulação de neurônios e sistemas de cérebros, como discutido por Perez e Cohen (2019). Todavia, quando se trata de uma incorporação parcial humana em forma de dados, os estudos são bem mais prováveis.

Ainda, como base para esse estudo, estão os avatares e chatbots. Para Galvão et al. (2017), as possibilidades de se imortalizar um usuário podem ser, atualmente, pela: a) geração de memoriais digitais, os quais mantêm registros online do usuário falecido, gerados em vida ou na forma de homenagens póstumas; b) criação de aplicações digitais, após análise do padrão de mensagens do usuário falecido, permitem conversar com este "chatbot", o qual virtualmente manda mensagens de textos similares às que poderiam ter sido enviadas pelo usuário em vida; c) transferência da mente humana de um usuário falecido para um corpo mecânico e, assim, o imortalizar via este corpo-conhecido como "avatar", com dados transferidos via software.

Todavia, pela transferência da mente, como discutido anteriormente, ainda não ser uma opção plausível, o avatar seria usado apenas como identidade do falecido, assim como é usado em diversos jogos e como apontado por Guo Freeman et al. (2020) em seu estudo sobre avatares em jogos de realidade virtual. Os avatares são uma extensão da vida real e servem como uma exploração da própria identidade.

\section{Metodologia}

O presente estudo consiste em uma pesquisa exploratória de abordagem qualitativa, conforme Gil (2002). Para coleta de dados foi realizada a técnica de questionário (GIL, 2002). O questionário era composto por questões objetivas e discursivas baseadas em um questionário prévio da pesquisa do grupo de pesquisa DAVI ${ }^{1}$, do Instituto de Computação da Computação da UFMT, que possui aprovação do Comitê de Ética em Pesquisa com Seres Humanos da Área das Ciências Humanas e Sociais da UFMT.

O questionário foi dividido em três seções. Na primeira seção, as questões eram voltadas para compreender a realidade social dos pesquisados e traçar um perfil que envolvia questões como gênero e religião. Também, questionamos se o pesquisado fazia uso em seu cotidiano de redes sociais, em caso afirmativo, era conduzido para questões que buscavam compreender como era essa utilização e se houve contato com pessoas falecidas, bem como, os sentimentos que emergiram desse contato. Na segunda seção do questionário, as questões tinham objetivo de compreender as percepções dos pesquisados sobre legado digital, caso afirmasse que não conheciam o significado, era aberta uma aba com a explicação. Também, questionamos sobre imortalidade digital, inteligência artificial, chatbot e avatares. Por fim, a terceira seção, era composta de questões sobre o uso dos dados pessoais para um sistema de avatares que armazena as informações do falecido. Também, questionamos sobre as suas preferências acerca da coleta de dados, e o que teria nesse sistema, na percepção dos pesquisados, bem como sobre a personalização, aplicação própria e gerenciamento do avatar.

\footnotetext{
${ }^{1}$ http://lavi.ic.ufmt.br/davi/
} 
O questionário foi elaborado via Google Forms e divulgado em redes sociais (Facebook, Whatsapp e Twitter), bem como em listas de transmissão tais quais a da Sociedade Brasileira de Computação ficando disponível entre 11/05/2021 e 08/06/2021, período no qual tivemos um retorno de 112 respostas. Para participarem da pesquisa, os internautas concordavam com o Termo de Consentimento Livre e esclarecido, podendo acessar a cópia dele no site do projeto ${ }^{2}$

Após a aplicação do questionário, foram feitas análises qualitativas. Para isso, as informações coletadas foram agrupadas e analisadas. Para tanto, foram separadas e lidas as opiniões fornecidas pelos participantes nos campos abertos para entender suas respostas e identificar os pontos de análise.

Em todas as questões do questionário, deixamos uma opção "outros", para que os participantes pudessem comentar livremente sobre as questões abordadas, assim, abordamos nos resultados, diversas reflexões apontadas ao longo do questionário. $\mathrm{Na}$ apresentação e análise dos dados, para manter a identidade dos participantes, estes foram nomeados da seguinte forma: a letra $\mathrm{P}$ de participante seguido de uma numeração sequencial. Exemplo: participante de número 1, foi denominada P1.

\section{Resultados}

Nessa seção serão apresentados os principais resultados da pesquisa, para tanto, trazemos inicialmente a caracterização dos participantes, os principais dados achados na pesquisa e, na sequência, a discussão realizada com as análises das respostas das perguntas feitas no questionário.

Apresentamos inicialmente o gráfico 1 e 2 que apresentam o gênero e a idade dos 112 participantes da pesquisa.

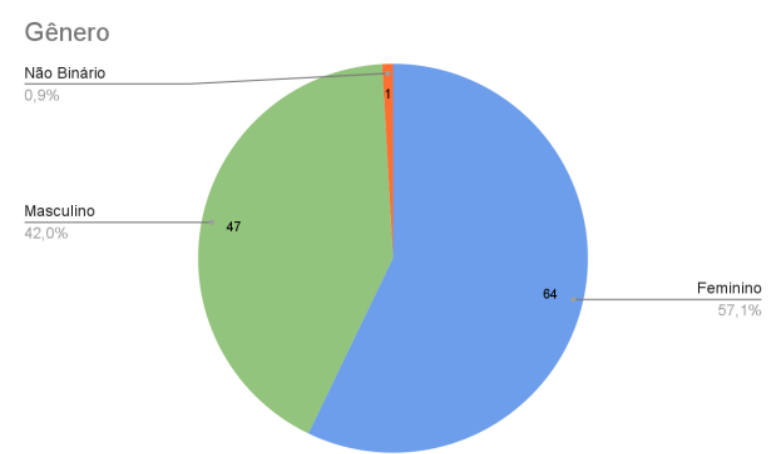

Gráfico 1. Gênero dos participantes

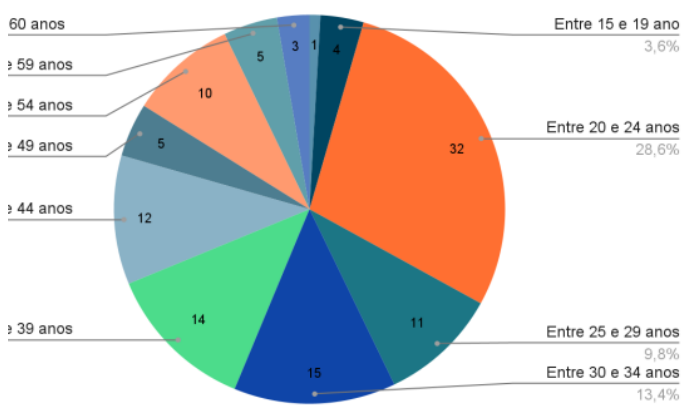

Gráfico 2. Idade dos participantes

Ressaltamos que a pesquisa foi realizada com pessoas aleatórias, no ambiente internet, sendo percebido que a maioria conhece em que consiste a imortalidade digital, inteligência artificial, chatbot e avatares. Os assuntos menos conhecidos são legado digital e imortalidade digital, conforme exposto no gráfico.

\footnotetext{
${ }^{2}$ https://avi.ic.ufmt.br/davi/artefatos/
} 


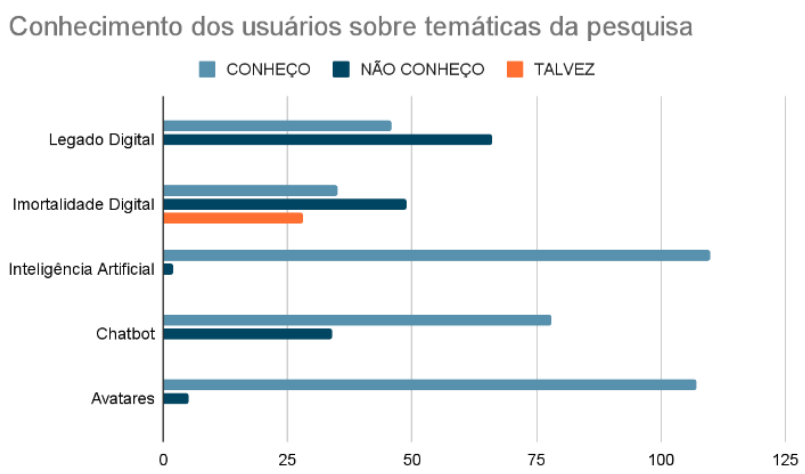

\section{Gráfico 3. Conhecimento dos usuários sobre temáticas da pesquisa}

\subsection{Interação póstuma em Redes sociais}

Como o foco do questionário foi coletar opiniões sobre a criação de um sistema de avatares de interação póstuma como forma de legado digital, primeiramente, foi necessário observar o uso dos participantes nas redes sociais. Dentre as 108 pessoas que disseram utilizar as redes sociais: o Facebook (79), Instagram (96), Twitter (54), Tiktok (29), Pinterest (36), Youtube (95) e Linkedln (58). Na opção "Outros" foi indicada ainda a utilização do Whatsapp (2), Reddit( 2), Kwai (1) e Researchgate (1).

Foi possível visualizar que grande parte (99 pessoas) conheciam alguém que estava nas redes sociais e veio a falecer, e interagiram de diversas formas com dados póstumos. A maior parte das interações são para lembrar-se da pessoa, ler recados e/ou ver fotos. Ainda, dentre a maioria, foram despertados sentimentos tais quais tristeza, estranhamento, desconforto, curiosidade, conforto e/ou tranquilidade. Mesmo havendo interação com as contas de pessoas falecidas em redes sociais, 65 pessoas nunca pensaram sobre o destino dos seus dados após sua morte nas redes sociais e diante disso, das 108 respostas, marcando quantas respostas desejassem: 60 gostariam que sua conta fosse um memorial, 31 gostariam que fossem enviados para uma plataforma específica de memoriais, 23 que fosse deletada, 20 ainda não sabem e outros 2 são indiferentes.

Dentre os recursos que gostariam de mostrar em seus perfis póstumos, marcando quantas opções desejassem, os principais foram: Informações básicas como nome (81), fotos e vídeos (87), causa da morte (31), religião (17), amizades (69), comentários (39), data da morte (1), coisas importantes e projetos que trabalhou durante a vida (1). Também observamos, entre os usuários que utilizam as redes sociais (108), que 63 pessoas conhecem a opção de configuração de herdeiro e 45 pessoas não.

\subsection{Utilização dos dados dos usuários em plataformas de simulação da vida}

Buscamos identificar a percepção dos usuários acerca da possibilidade de utilização dos dados dos usuários em plataformas de simulação da vida: 46 pessoas não aceitariam, 37 aceitariam, 28 não sabem opinar e 1 a depender da situação. Neste ponto, percebemos uma grande divergência de opiniões, o que indica necessidade de maior debate, reflexão sobre o assunto ou transparência das possibilidades de uso de dados póstumos.

Fica evidente também uma incerteza e insegurança diante dos procedimentos para a realização de tal recriação, os participantes acreditam que deve haver uma maior discussão da temática, como exposto por P12: "A recriação da vida em qualquer forma, mesmo que digitalmente, é uma questão ainda pouco amadurecida e que pode afetar de maneiras imprevisíveis aqueles que venham a interagir com ela. No momento acredito que este tipo de recriação deva ser evitado.". 
Existe ainda uma preocupação com a utilização de forma má intencionada dos dados, como podemos observar no comentário de P43, que afirma "ideia, em si, até é interessante. Mas deve ter autorização expressa da pessoa. Além de ter problemas pós direitos autorais, onde pessoas má intencionadas podem utilizar dessa tecnologia para denegrir, zombar ou utilizar isso para questões ideológicas ou políticas, isso pode causar dor e sofrimento nos descendentes da pessoa". Percebemos que o participante pensou em crimes de falsidade ideológica, o que é algo altamente debatido no quesito de leis no ciberespaço. Ainda, nesta perspectiva, temos o comentário de P17 que diz "Eu não acho eticamente legal. Mesmo porque fraudadores podem utilizar fotos do falecido para cometer crimes de falsidade ideológica".

Outro ponto abordado pelos participantes foram fatores psicológicos, em que alguns mencionam problemas como apego, que podem prejudicar o luto, como mencionado por $\mathrm{P} 82$ “..Acredito que isso pode provocar inúmeros prejuizos psicológicos para as pessoas que estão enfrentando o luto". P41 também afirma que " $O$ ato de "ressuscitar" alguém, mesmo que virtualmente, pode desencadear diversas emoções e trazer a tona toda a emoção da perca, além de excluir o processo de luto que a pessoa teve/tem. No meu ponto de vista é como uma tortura emocional". P25 traz como sugestão que "Seria interessante para personalidades públicas" talvez a partir dessa utilização, as pessoas pudessem compreender os limites e possibilidades de tais iniciativas e pudessem compreender os benefícios para a vivência do luto.

\subsection{Utilização de Chatbot e Avatares para o contato póstumo com o falecido}

Em relação à conversação com um falecido através do chatbot, percebemos uma negação maior: 75 pessoas não gostariam de conversar com um falecido através de um chatbot, 28 talvez e 9 gostariam. Os motivos apresentados pelos participantes que não gostariam foram por considerar: desrespeitoso (P15), estranho (P32), medo (P18, P73), invasivo (P19), confuso (P101), prejudicial ao luto (P92), dentre outras.

Outros participantes demonstraram novamente muita insegurança em relação à operacionalização, P64 afirma: "[...] o bot realmente teria noção de todo o contexto para poder opinar? Seria como consultar astrologia para decisões políticas". Ainda, nesta perspectiva, P28 afirma que "Seria um desafio para os algoritmos mapearem as reações das pessoas sobre um tema e então "aconselharem" sobre este tema através de um chatbot, quando consultados após a morte de uma pessoa". Foi abordado ainda pelo P61 a preocupação com as implicações éticas e P45 considera que estaríamos infringindo a memória do falecido.

Um dos participantes (P103), entretanto, considera que "eventualmente seria acolhedor ouvir minha avó me contando sobre fatos que só soube depois de sua morte". P11 comentou que "Acredito que pode ter um efeito terapêutico, principalmente para lidar com assuntos não resolvidos. Mas imagino que muita gente pode ter uma relação não saudável com essa tecnologia". Percebemos assim, que existe muita insegurança quanto a utilização de chatbots, segundo o P39 "esse tipo de tecnologia pode romper com certos limites entre a vida e a morte", o que segundo P59 seja complicado tendo em vista que a população brasileira não está preparada para essa utilização, pois o tema da morte ainda é um tabu, o que dificulta o processo de luto dos familiares mais próximos

No que se refere a avatares, 57 pessoas não gostam da ideia da criação de um avatar após o falecimento do usuário que reúna informações da vida, apresente fotos e 
possa até conversar por chatbot, já 43 pessoas gostam da ideia, 2 nunca pensaram sobre isso e 10 acham interessante apenas como memorial, além de outras respostas. É interessante perceber que várias pessoas gostariam da ideia de avatar apenas como memorial, sem a parte do chatbot.

Nessa mesma linha, 62 pessoas não gostariam de ter um avatar mesmo que alguns achem interessante a implementação de um, 26 gostariam e 24 não souberam responder, além das outras justificativas, uma em específico, gostaria apenas se fosse uma pessoa notável e nas palavras de P13: "Depende de quando ocorra a minha morte. Sou mãe de uma criança de 3 anos. Se eu morrer ainda na infância e adolescência dela gostaria que ela pudesse "conversar" comigo. Saber minha opinião sobre alguns fatos... Talvez eu tivesse a chance de compartilhar com ela minha percepção sobre a vida e isto pudesse ajudá-la no seu próprio caminhar."

Para o sistema de avatares, foram incluídas algumas opções para que os participantes pudessem escolher, além de poder recomendar algumas funcionalidades, dentre as opções:

- Site específico com diversos avatares de pessoas falecidas, como uma espécie de biblioteca (20)

- Espaço para comentários, publicações de fotos e conteúdos para somar ao perfil de avatar da pessoa (38)

- Avatar que mostra apenas o que é buscado (Ex: fotos com animais) (11)

- Avatar que simule a personalidade do falecido (27)

- Fornecimento de dados durante sua vida para a plataforma do avatar (31)

- Busca do avatar com a inteligência artificial nas redes por suas informações somente após o falecimento (19)

- Conversa por chatbot (17)

- Personalização do avatar (Acessórios, roupas) (26)

- Seleção de várias ou uma pessoa para gerenciar o avatar (19)

Como parte da opinião dos participantes sobre esse sistema, alguns apontam que o único problema seria o chatbot, pois segundo os participantes além de ser estranho, pode prejudicar o luto ou criar dependências emocionais. No entanto, gostam da ideia do sistema oferecer a opção para o usuário selecionar, entre seus dados fornecidos durante a vida, o que pode ser apresentado, e também, possuir um avatar para mostrar ao visitante as memórias após sua morte.

\section{Considerações finais}

O tema da imortalidade digital é de fato muito sensível, porém importante de ser discutido, principalmente para medir a aceitação das pessoas, trazendo o tema para o debate. Com as respostas, é possível perceber que as opiniões dos participantes estão divididas, alguns acham interessante o uso da imortalidade digital na ajuda com o luto de entes queridos e outros acham desrespeitoso. É possível identificar também que para um possível sistema de avatares, a maioria dos participantes não gostariam de conversar com um chatbot mas gostariam de ter um avatar da pessoa falecida com memórias, isso pode levar a um estudo futuro para a projeção de um sistema mais focado em memórias. Ainda, o estudo nos permitiu observar a importância da coleta de dados dos usuários para questões que podem afetar o indivíduo. Acrescenta-se à discussão também, a importância de ressaltar a questão sobre a maturidade da tecnologia. Ao que indica, algumas pessoas 
possuem sentimentos de medo em relação aos avatares e chatbots que influenciaram suas respostas. No entanto, sistemas de perguntas e respostas e diálogo ainda são campos relativamente novos e pouco desenvolvidos, ou seja, essa percepção dos participantes não condiz com a realidade do que pode ser feito com a tecnologia atualmente.

Como parte das limitações da pesquisa cita-se a necessidade de ajustar o estudo para uso de questionários, em função da pandemia. O estudo estava previsto e autorizado pelo comitê de ética para realização com questionários e grupo focal presencial. Todavia, com a readequação dos procedimentos junto ao comitê, não houve tempo hábil para realizar um grupo focal virtual com os participantes que demonstraram interesse nas próximas etapas da pesquisa. Assim, esse é um trabalho futuro endereçado nesta pesquisa, que permitirá o aprofundamento de dados. Com base neste, seria possível avançar no projeto de sistemas neste campo, utilizando, inclusive, técnicas como a prototipação com avatares, a partir de dados, a fim de reconstruir a história de uma pessoa.

Fica evidente nos achados da pesquisa a necessidade de maior reflexão sobre a temática, sugerimos assim, que sejam incorporadas nas discussões a possibilidade de uso de dados póstumos para processos de manutenção das memórias e contribuições destas para os processos de vivência e superação do luto. Também, é salutar, incorporar maiores discussões sobre a temática da morte, para que ela deixe de ser um tema interdito, contribuindo assim, para que as discussões sobre imortalidade digital sejam realizadas com maior naturalidade. Neste sentido, percebe-se como importante que essa discussão faça parte do processo formativo de estudantes, em escolas e universidades.

\section{Referências}

Bell, G. and Gray, J. (2001) Digital immortality. Communications of the ACM, v. 44, n. 3, p. 28-31, 2001.

Freeman, G. et al. (2020) My Body, My Avatar: How People Perceive Their Avatars in Social Virtual Reality. In: Extended Abstracts of the 2020 CHI Conference on Human Factors in Computing Systems. 2020. p. 1-8.

Galvão, V. and Maciel, C. (2020) Reflexões sobre a imortalidade digital em contextos educativos. Communitas, v. 4, n. 7, p. 59-78, 29 maio 2020.

Galvão, V. F. et al. (2017) Life beyond the physical body: The possibilities of digital immortality. In: 2017 XLIII Latin American Computer Conference (CLEI). IEEE, 2017. p. 1-10.

Gil, A. C. (2002) Como elaborar projetos de pesquisa. São Paulo: Atlas, 2002.

Maciel, C. and Pereira, V. C. (2012) The internet generation and its representations of death: considerations for posthumous interaction projects. In: Proceedings of the 11th Brazilian Symposium on Human Factors in Computing Systems. Porto AlegreRS,Brasil:Brazilian Computer Society, 2012. p.85-94.

Perez, M. N. and Cohen, R. (2019) Uploading the Mind: The Basics and Ethics of Whole Brain Emulation. Science In Society Review, 2019.

Prates, R. O. and Barbosa, S. D. J. (2006). Avaliação de interfaces de usuário-conceitos e métodos. In: Jornada de Atualização em Informática do Congresso da Sociedade Brasileira de Computação, Capítulo. sn, 2003. 